\title{
A RELAÇÃO ENTRE MEMÓRIA, AFETOS E PERFORMANCE DE MÚSICA INSTRUMENTAL
}

\section{RESUMO:}

\section{Stéfano Paschoal ${ }^{1}$}

O objetivo principal deste trabalho é apresentar uma relação possível entre memória, afetos e performance de música instrumental. Abrange a música composta predominantemente entre os séculos XVI e XIX e, por conseguinte, períodos que diferem significativamente entre si. Parte das discussóes sobre memória, considerada aqui a quarta parte da Retórica (segundo sua divisão clássica) e também a arte da memorização (mnemônica), e sobre afetos, para, entâo, culminar na questão que motivou de forma mais intensa suas investigaçóes: o papel da memória e da memorização dos afetos na performance de música instrumental. Através de uma revisão - de modo delimitado, pela natureza deste trabalho - da literatura sobre afetos na Retórica de Aristóteles, e apoiados em diversos outros filósofos e autores, traçamos uma relação entre memória, afetos e performance musical, indicando como o intérprete lida com os afetos da obra que executa - no momento da execução - e como deve se comportar, emocionalmente, para que sua audiência seja tomada por esses mesmos afetos. Por lidarmos de forma específica com as relações entre retórica e música - promovidas por Lutero nas reformas propostas às Lateinschulen - são numerosas as comparaçóes entre o orador e o intérprete.

\section{PALAVRAS-CHAVE:}

memória; afetos; performance musical.

\footnotetext{
ABSTRACT:

The aim of this paper is to present a possible relationship between memory, affections and instrumental music performance. It comprises the music composed predominantly between the sixteenth and nineteenth centuries, and therefore, periods which differ substantially. It starts off with discussions regarding memory, con-
}

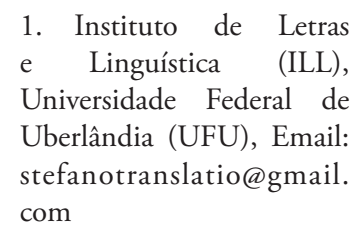


sidered herein, a quarter of what is understood as the classical division of Rhetoric, as well as the art of memory (mnemonics), and affections, to then culminate in the question which more intensely motivated its investigations: the role of memory and the memory of affection in instrumental music performance. By means of a review - in such a way, the nature of this work - the literature on emotions according to the Rhetoric of Aristotle, and the support of several other philosophers and authors, we draw a relationship between memory, affections and musical performance, pinpointing how the performer handles the affections the work involves while being performed - at runtime - and how to behave emotionally, so that one's audience is taken by those very same affections. Dealing specifically with the relationship between rhetoric and music - promoted by Luther in the proposed Lateinschulen reforms - the comparisons between the speaker and the interpreter are plentiful.

\section{KEYWORDS:}

memory; affections; musical performance.

\section{MEMÓRIA}

Neste breve estudo, propomo-nos, através da investigação de algumas definiçốes e de discussóes acerca da memória e dos afetos, tratar de suas relaçóes com a performance de música instrumental.

Para discorrermos sobre o tema proposto, são necessários, de início, dois breves esclarecimentos: o primeiro diz respeito ao conceito de memória, aqui considerada a quarta parte da Retórica, conforme sua divisão clássica, e também em sua acepção mais moderna, habilidade de memorização (mnemônica). O segundo diz respeito à música instrumental: embora nos abstenhamos de exemplos musicais, consideramos, neste trabalho, as composiçóes originadas predominantemente entre os séculos XVII e XIX, e nossas ideias remetem, por questôes de formação, mais diretamente à música para teclado.

O segundo esclarecimento indica que consideramos a música num período que a abrange tanto como objeto de estudo da Retórica quanto objeto de estudo da Estética. Náo obstante as relaçôes entre retórica e música terem ocorrido de forma privilegiada na música de séculos XVI e XVII a partir das La- 
teinschulen de Lutero e o fato de ser a música a partir do século XVIII um objeto "exclusivo" da Estética, a música a partir do século XVIII náo prescinde de elementos retóricos em sua constituição, e nem deixa de possuir elementos de sua forma composicional comparáveis a expedientes retóricos.

A memória ou arte da memória, discutida desde a Antiguidade clássica, parece ter ganhado força no Frühneuzeit (cerca de 1400-1750), quando surgem diversos tratados dedicados exclusivamente a ela, como vemos no Historisches Wörterbuch der Rhetorik:

O número de tratados mnemônicos surgidos como partes independentes da Retórica aumenta táo subitamente no Frühneuzeit, que é possível falar aqui legitimamente de um florescimento de uma ars memorativa. Tendo início com a invenção da imprensa, comprovam-se, até o ano de 1700, na Europa - excetuando-se a parte eslava - aproximadamente 800 autores que escreveram cerca de 1000 tratados mnemônicos, dos quais se publicaram 2500 ediçōes $^{2}$ (UEDING, p. 1053, vol. 5).

$\mathrm{Na}$ Antiguidade clássica latina, as instruçôes sobre memória estão presentes predominantemente em três obras: $D e$ Oratore, de Marco Túlio Cícero; Ad C. Herennium libri IV, atribuída durante a Idade Média a Cícero, mas hoje considerada de autoria anônima, e Institutio oratoria, de Marcos Fábio Quintiliano. Das três obras, a mais importante para o estudo da memória é a Rhetorica ad Herennium (doravante $R h$. ad H.), conforme vemos abaixo, de acordo com Yates (2007):

Em Roma, ca.86-82 a.C., um professor de retórica desconhecido compilou, para seus alunos, um manual prático que imortalizou não o seu próprio nome, mas o do homem ao qual o dedicara. É lamentável que essa obra, tão importante para a história da arte clássica da memória [...] não tenha outro título a não ser o pouco informativo Ad Herennium. [...] O imenso peso da história está presente na seção do Ad Herennium sobre a memória. Ela remete a fontes gregas de ensino da memória, provavelmente tratados gregos de retórica já desaparecidos. É o único tratado latino conservado sobre o tema, já que os comentários de Cícero e Quintiliano não são tratados completos e pressupóem que o leitor está familiarizado com a memória artificial e sua terminologia. Desse modo, é realmente a principal fonte - na realidade
2. "In der Frühen Neuzeit steigt die Zahl der mnemonischen Traktate, die unabhängig von Rhetorikern entstanden, sprunghaft an, so da $\beta$ man hier legitimerweise von der Blütezeit der ars memorativa sprechen kann. Beginnend mit der Erfindung des Buchdruckes, lassen sich bis zum Jahr 1700 in Europa den slawischen Teil einmal ausgenommen - rund 800 Autoren nachweisen, die circa 1000 mnemonische Traktate verfaßt haben, welchen ihrerseits in gut 2500 Druckausgaben nachzuweisen sind“. Nossa tradução. 
3. "Naturalis est ea, quae nostris animis insita est et simul cum cogitatione nata; artificiosa est ea, quam confirmat inductio quaedam et ratio praeceptionis". Nossa tradução.

4. "Constat igitur artificiosa memória ex locis et imaginibus. Locus appelamus eos, qui breviter, perfecte, insignite aut natura aut manu sunt absoluti, ut eos facile naturali memória comprehendere et amplecti queamus: ut aedes, intercolumnium, angulum, fornicem et alia, quae his similia sunt. Imagines sunt formae quaedam et notae et simulacra eius rei, quam meminisse volumus". Tradução de Adriana Seabra e Ana Paula Celestino Faria. a única completa - para a arte clássica da memória, tanto grega quanto romana (p. 21-22).

$\mathrm{O}$ autor da $R h$. ad $H$. divide a memória em memória natural e memória produzida pela arte, denominada por alguns memória artificial. Segundo ele, "[memória] natural é aquela situada em nossa mente e nascida junto com o pensamento; artificial é aquela que certa indução e método preceptivo consolidam" " (RH. AD H., p.183). Para o autor da Rh. ad H., aqueles que não possuem a memória natural podem adquirir a memória produzida pela arte (ou artificial) e, assim como a memória artificial, a natural pode ser reforçada por uma série de exercitaçóes.

As teorias da memória predominantes em épocas posteriores à $R h$. ad $H$. seguem a tópica de que a memória artificial se constitui de lugares e imagens. Ainda que se alterem - devido principalmente a fatores históricos, sociais e temporais - as características de lugares e imagens ao se discorrer sobre memória, "lugar" permanece "lugar" e "imagem" permanece "imagem". O autor da Rh. ad. H. nos diz:

A memória artificial constitui-se de lugares e imagens. Chamo lugar aquilo que foi encerrado pelo homem ou pela natureza num espaço pequeno inteira e distintamente, de modo que possamos facilmente percebê-lo e abarcá-lo com a memória natural: como uma casa, um vão entre colunas, um canto, um arco e coisas semelhantes. Já imagens são determinadas formas, marcas ou simulacros das coisas que desejamos lembrar ${ }^{4}$ (RH. Ad H., 2005, p. 183).

Em princípio, o método de lugares e imagens pode funcionar para qualquer pessoa. Consideremos, contudo, que a necessidade de memorizaçáo depois do advento da imprensa é bastante diversa da necessidade que tinham os oradores da Antiguidade. Para Yates, "a palavra 'mnemotécnica dificilmente transmite o que poderia se assemelhar à memória artificial de Cícero". Em Cícero (De Oratore, II, lxxxvi), acerca do conhecido caso de Simônides de Ceos, ${ }^{5}$ temos:

Ele (Simônides) inferiu que pessoas que desejam treinar essa faculdade (da memória) precisam selecionar lugares e formar imagens mentais das coisas que querem lembrar, e guardar essas ima- 
gens nesses lugares, de modo que a ordem dos lugares preserve a ordem das coisas, e as imagens das coisas denotem as próprias coisas, e devemos empregar os lugares e as imagens assim como uma tábua de cera sobre a qual são inscritas letra (apud YATES, 2007 [1966], p. 18).

A interpretação de Yates acerca desse trecho fornecerá material para nossa discussão acerca da memória na performance musical, já que conduz a exposiçóes acerca da possibilidade de memorização através dos órgãos de sentido. Vejamos:

As fontes clássicas parecem descrever técnicas que dependem de impressóes visuais de uma intensidade inacreditável. Cícero enfatizava que a invenção da arte da memória por Simônides náo radicava apenas na sua descoberta da importância da ordem seqüencial para a memória, mas também na de que o sentido da visáo é o mais forte de todos os sentidos (YATES, 2007 [1966], p. 20, grifo meu).

Chama a atenção, nesta interpretação de Yates, o fato de, para a memória, a visáo ser considerada o mais forte de todos os sentidos. $\mathrm{Na}$ Antiguidade, acreditava-se que a memória era uma capacidade da alma. Pitágoras e Empédocles, por exemplo, atribuem à alma, através da memória (lembrança, reminiscência) o dom de ser uma parte da verdade, um conceito que tem consequências na filosofia de Platáo. De acordo com a filosofia platônica, a alma é um princípio automovente que coloca em movimento o corpo: esta alma, imortal, carrega consigo tudo o que já aprendeu alguma vez, sendo o ato do aprendizado, por conseguinte, nada além de um ato de lembrança ou memória, como podemos ver em Souza:

Uma palavra de antigos poetas, diz Sócrates citando versos de Pindaro, revela que a alma é imortal, ora completando uma vida, o que os homens chamam de morte, ora iniciando outra, o que se denomina nascimento. Imortal e muitas vêzes nascida, ela viu tôdas as coisas (lit. tudo o que é) neste mundo e no Hades, e não há nada que náo tenha aprendido. Assim, de tudo ela pode se lembrar, de tudo que já viu antes. Como a natureza é homogênea, uma coisa que o homem se lembre pode levá-lo a descobrir tôdas as outras (SOUZA, 1971, p. 52-53).
5. Simônides de Ceos, num banquete oferecido por um nobre de Tessália, honrou em um poema o seu anfitrião, mas também Castor e Pólux. O anfitrião disse que pagaria apenas a metade do combinado, sugerindo a Simônides que cobrasse a outra metade dos deuses gêmeos. Logo depois, Simônides foi avisado de que dois jovens o aguardavam à porta. Chegando ali, não encontrou ninguém e, de súbito, o teto do salão em que se realizava o banquete desmoronou, matando $\mathrm{o}$ anfitrião e todos os outros convidados. Os corpos ficaram tão deformados que não podiam ser reconhecidos pelos parentes. Simônides então lembrou-se da sequência em que todos estavam sentados, identificando aos parentes quais eram os seus mortos. 
Souza, ao discorrer sobre a teoria platônica da reminiscência, diz que, no diálogo Menon, "a alma encarna-se sucessivamente e sua reminiscência, motivada pela interrogação, é fundamento de ciência" (1971, p.55); no Fédon, "a alma nesta vida vê os objetos sensíveis e lembra-se dos inteligíveis, e essa reminiscência permite estabelecer entre os primeiros e os segundos a mesma relaçáo que se faz entre imagem e realidade, entre ilusão e verdade" (1971, p.55) e, no Fedro, "a alma decai nêste mundo e sua reminiscência, motivada pelo amor, é fundamento de filosofia, que novamente a eleva" (1971, p.55). Reminiscência, lembremo-nos, pode significar, em princípio, lembrança ou memorização. A definição que melhor se adéqua aos propósitos deste trabalho é a segunda, já que abrange um conceito, para nós, de fundamental importância: a imagem.

Para Aristóteles, a memória está relacionada à capacidade de aprendizado, como vemos abaixo:

(2) Por natureza, seguramente, os animais são dotados de sensação, mas, nuns, da sensação não se gera a memória, e noutros, gera-se. Por isso, estes são mais inteligentes e mais aptos para aprender do que os que são incapazes de recordar. Inteligentes, pois, mas sem possibilidade de aprender, são todos os que não podem captar os sons, como as abelhas, e qualquer outra espécie parecida de animais. Pelo contrário, têm faculdade de aprender todos os seres que, além da memória, são providos também deste sentido (ARISTÓTELES, 1984, p.11).

Julgamos necessário, neste momento, mostrar que, não obstante relacionar a memória à capacidade de aprendizado e defender um conhecimento "prévio", no que diz respeito à reminiscência, Aristóteles não aceita a reminiscência tal qual concebida por Platáo, como vemos em Figueiredo:

[Conhecimento prévio] que permitirá a Aristóteles responder ao paradoxo do Ménon 80d-c, pela afirmaçáo de que o conhecimento demonstrativo de uma dada entidade supóe sempre o conhecimento prévio da definição dessa entidade, conhecimento esse que é, relativamente a essa entidade, um conhecimento implícito, que se tornará explícito durante o processo de demonstração; deste modo, ao aprendermos, tornamos explícito - i.e., reconhecemos - algo que já sabíamos antes, mas apenas implicitamente (v.APo.I,1, especialmente 71a29ss). Deste modo, Aristóteles pode aceitar a noção de aprendizagem como reconheci- 
mento, sem ter que aceitar igualmente a de reminiscência, tal como ela é vista por Platáo (FIGUEIREDO, 1993p. 45).

Voltamos neste momento à discussão acerca da primazia dos órgáos de sentido. Anteriormente, de acordo com uma citação de Yates, apontamos que, para Cícero, o órgão de sentido mais importante era a visáo. Partindo disso, poderíamos traçar um paralelo, ainda que superficial, entre o Arpinate e Aristóteles, já que suas concepçóes acerca desta primazia parecem coincidentes, como vemos no Livro I de sua Metafísica:

Todos os homens têm, por natureza, desejo de conhecer: uma prova disso é o prazer das sensaçóes, pois, fora até da sua utilidade, elas nos agradam por si mesmas e, mais que todas as outras, as visuais. Com efeito, não só para agir, mas até quando não nos propomos operar coisa alguma, preferimos, por assim dizer, a vista ao demais. A razão é que ela é, de todos os sentidos, o que melhor nos faz conhecer as coisas e mais diferenças nos descobre (ARISTÓTELES, 1984, p. 11).

Buscamos ainda em alguns filósofos epicuristas, das ciências naturais, o que dizem acerca de assimilação e memória. Epicuro, ao tratar deste tema, em sua Carta a Heródoto (4653), diz que "é realmente necessário assumir que algo de fora entra em nós, e nisto vemos as formas a partir das quais formulamos (interpretamos) os pensamentos" (LONG e SEDLEY, 2000, p. 84). Podemos inferir daí que a formulação do pensamento está relacionada àquilo que se vê e, assim, que a visão tem papel primordial. Acerca do mesmo tema, Lucrécio (4.722-822, p.87) discorre:

Tu poderás facilmente compreender que as coisas acontecem tal como digo do seguinte modo: nesse ponto, aquilo que vemos com o espírito deve necessariamente suceder de maneira semelhante. Demonstrei que, através das imagens que atingem meus olhos, sempre vejo aquilo de que se originam essas imagens, por exemplo, um leão. Assim, poderás dizer agora que o espírito é, igualmente, movido através de imagens de leóes e também através de outra coisa, que ele vê, e, de fato, com os olhos, a não ser que aquilo que veja tenha constituiçáo mais apurada ${ }^{7}$ (apud LONG e SEDLEY, 2000, p. 87).

6. "In der Tat ist es auch nötig anzunehmen, da $\beta$ es etwas von außen in uns Eintretendes ist, auf das hin wir die Gestalten sehen und Gedanken von ihnen fassen". Nossa tradução.

7. “(5) $\mathrm{Da} \beta$ es sich so abspielt, wie ich sage, kannst du folgendermaßen leicht erkennen. Insofern das, was wir mit dem Geist sehen, mu $\beta$ es notwendig auf eine ähnliche Weise zustandekommen. Nun habe ich gezeigt, da $\beta$ ich jeweils durch die Bilder, die meine Augen anstoßen, das sehe, wovon sie Bilder sind, z.B. einen Löwen. Daher kannst du 
nun sagen, da $\beta$ der Geist auf ähnliche Weise durch Bilder von Löwen bewegt wird und ebenso durch das andere, was er sieht, und zwar um nichts weniger als die Augen, außer da $\beta$ das, was er sieht, feiner ist". Nossa tradução.
Nota-se, na citação de Lucrécio, que é a visão, sobretudo, que permite ao espírito a formação das imagens em seu âmago, das quais depreende o entendimento das coisas. Observamos mais uma vez, considerando que a memória exige uma disposição de lugares e imagens, a função primordial da visão para esta ciência.

\section{MEMÓRIA DO INTÉRPRETE}

Quanto à formação de uma memória auditiva - em relação a uma peça a ser executada pelo intérprete - poder-se-ia dizer que é formada primordialmente a partir da visão? A pergunta nos levará a investigaçóes acerca da audição e da escuta. $\mathrm{O}$ estudo de uma partitura passa, naturalmente, pela visão, pois lemos as notas musicais. Muitos músicos desenvolvem o que chamamos de ouvido interno e, a partir disso, torna-se possível, ao "ler" as notas (longe de um instrumento), saber como soa a música, ou, ao menos, como deve soar. Essa habilidade, contudo, não é própria a todos.

Discutir a primazia da visão para a memória conduz-nos a diversas reflexôes sobre a memória musical. Há relativamente muitos casos de pianistas que conseguem memorizar suas peças com o trabalho de leitura "fora do instrumento", mas não se ouve falar tão frequentemente de pianistas que tenham conseguido memorizar as peças apenas ouvindo-as, por exemplo, de uma gravaçáo - mesmo porque cada intérprete tem suas individualidades, concepçóes e limitaçóes. Ao ouvir uma gravação de uma peça desconhecida algumas vezes, podemos cantarolar em nossas mentes a peça toda, mesmo sem nunca termos visto a partitura: trata-se de outro tipo de memória que náo interfere necessariamente na performance da música ao instrumento.

Epicuro, em outro trecho de sua Carta a Heródoto, diz:

Outra coisa: a audição também provém de um fluxo emanado de algo que pode ser uma voz, um som, um ruído, ou que produza de qualquer modo uma afecção auditiva. Esse fluxo divide-se em partículas constituídas de forma semelhante que mantêm entre si certa simpatia e uma unidade característica, que permite que nos remetamos ao objeto emissor, produzindo, o mais frequentemente, a sensação que corresponde ao objeto ou, senáo, ao menos 
evidencia a existência de algo exterior a nós. Portanto, sem certa simpatia resultante do objeto e que remete a ele, tal sensaçáo representativa não poderia suceder ${ }^{8}$ (ÉPICURE, 2009, p 99-101).

A "sensação representativa" ou "assimilação" relaciona-se com certa imagem, que deve, por sua vez, ser posta num lugar. Segundo Epicuro, a unidade das partículas constituídas de forma semelhante e que guardam entre si certa simpatia ao menos "evidencia a existência de algo exterior a nós". A memória auditiva, a priori, também evidencia a existência de algo exterior a nós - o som - mas, uma vez gravado no espírito o resultado deste "algo exterior", ele é dispensado. Por outro lado, exige-se o elemento "visual": a partitura, através da qual os "sons", já "assimilados e incorporados à memória", são evocados.

Chegamos a uma questão que, certamente, mais contribui para a perpetuação de um conflito do que para sua solução: o que seria mais importante para a memória musical, a visão ou a audição? Talvez não seja possível hierarquizar os órgáos de sentido para a memória musical. Todavia, se levarmos em conta que, para a memória, tudo se transforma em imagens, a visão seja mais importante. Ocorre que as imagens produzidas na memória - no caso da memorização de uma peça musical embora se deem mais comumente através da "leitura" de uma partitura, só é possível a partir da produçáo "interna” de sons na mente do intérprete-leitor, e suas imagens, se não são elas propriamente acústicas, são predominantemente formadas a partir dos sons, e não da visão. Assim vemos que o embate náo parece passível de solução: tudo se forma a partir da audição, mas não é possível, ao intérprete - depois do advento da notação musical e, principalmente, nos séculos da Idade Moderna - imaginar o som da composiçáo alheia, pela primeira vez, sem sua "representação gráfica", ou seja, sem a partitura, que requer a visão, ou seja, há aí simultaneidade de habilidades que envolvem os dois sentidos.

Vimos que a ars memorativa, com suas especificidades, permite ao intérprete assimilar e memorizar os sons, formando imagens nos lugares da memória, que, por conseguinte, possibilitarão a ele a performance de música instrumental: em público ou não, embora a execuçáo em público seja mais frequentemente objetivo dos intérpretes.
8. "Autre chose: l'audition aussi provient d'un flux émanant de ce qui fait entendre une voix, un son, un bruit, ou produit de quelque manière une affection auditive. Ce flux se répand divise em petites masses formées de parties semblables, qui maintiennent à la fois une certaine sympathie entre elles et une unité caractéristique, lesquelles permettent de remonter à l'objet émetteur, em produisant, le plus souvent, la sensation qui correspond à l'objet, ou, sinon, en redant simplement manifeste son existence hors de nous. Car, sans une certaine sympathie issue de l'objet et renvoyant à lui, une telle sensation representative ne pourrait avoir lieu". Nossa tradução 


\section{ESCUTA E MEMÓRIA}

Passaremos neste momento a investigar o processo de escuta do intérprete. Partimos do pressuposto de que os fatores que influenciam a leitura mental de uma partitura influenciarão também a performance: a partir do que se planeja é que se define como se vai executar a peça.

Em primeiro lugar, cabe observar que, ao ler a partitura, o intérprete deve conhecer, dentre outras coisas, a estrutura da peça que executará (gênero), o estilo do compositor, seus traços individuais e as características gerais advindas do movimento estético em que está abrigado. Esses são alguns fatores externos que influenciam diretamente as escolhas criativas do intérprete e fazem parte do todo que, mesmo involuntariamente, será parcial ou inteiramente memorizado.

Chueke, ao discutir os estágios de escuta durante a preparação e a execução pianística, divide-os em três. Em resumo, "o primeiro envolve a escuta interior ou a 'escuta da partitura', o segundo consiste no trabalho técnico conscientemente guiado pela escuta anterior e o terceiro aborda a execução propriamente dita" (CHUEKE, 2015, p. 112). Para nós, é de fundamental interesse o primeiro, a escuta da partitura, estágio no qual, segundo a autora, "o pianista constrói uma imagem da obra, definindo um objetivo musical que lhe serve de guia durante a preparaçáo" (p. 112, grifo meu). A primeira pergunta dirigida a pianistas entrevistados contém trechos de Arnold Schönberg e Robert Schumann, afirmando que o primeiro "ensinava seus alunos a nunca tocarem uma peça que estivessem estudando pela primeira vez antes de lê-la cuidadosamente em silêncio, construindo uma imagem sonora" (apud CHUEKE, 2015, p. 113, grifo meu) e que o segundo "costumava dizer que os músicos deveriam ser capazes de 'escutar a partitura'.” (apud CHUEKE, 2015, p. 32).

A autora apresenta os estágios de escuta numa ordem determinada, mas náo acreditamos que o terceiro - um nível mais elevado, em que certas construçóes já foram definidas - ocorra sem o auxílio dos outros dois. Ao mesmo tempo em que são enumerados numa ordem distinta, parecem poder coexistir, pois o terceiro deles somente se poderá realizar com o auxílio dos outros dois, através da memória. 
Se a imagem da obra não for mantida na memória do intérprete, então o terceiro estágio - quando se comprova se o intérprete conseguiu escutar a obra, de fato, cai por terra. Trata-se, assim, de uma escuta durante a performance, e que pressupóe dois estágios anteriores, necessariamente MEMORIZADOS. Caso contrário, o objetivo musical que lhe serviu de preparação não é alcançado.

Ao se falar de preparação musical, ou seja, um estágio de escuta que prioriza a preparação musical, lidamos com a disposição de ideias (dispositio), atrelada à memória, já que parece haver aí, de fato, uma organização das imagens em seus loci específicos: um processo ocorrido mesmo inconscientemente. Ilustra esse caso, por exemplo, um trecho da segunda pergunta de Chueke, em relaçáo ao segundo estágio de escuta, em que ela cita Ewen (1943 apud CHUEKE, 2015, p.120) compositor, contrabaixista e regente Kossevitzky "costumava aprender uma obra lendo-a primeiro do começo ao fim, como um romance, e depois, relendo-a, fazia anotaçóes sobre os efeitos que desejava obter". A releitura com anotaçóes de efeitos a serem obtidos assemelha-se ao um trabalho de dispositio, ou seja, organização de ideias e afetos da peça a ser executada.

Nas entrevistas feitas por Chueke, o pianista Rudolf $\mathrm{Bu}-$ chbinder responde à primeira pergunta - o que se busca ao explorar pela primeira vez a partitura de uma obra que pretende incluir no repertório - que um dos princípios primordiais para se aprender uma peça é não somente ler, mas ouvir (CHUEKE, 2015, p. 113). Em resposta à mesma pergunta, o pianista Alfons Kontarsky diz que um dos métodos que utiliza para aprender uma peça "consiste na leitura da partitura, do começo ao fim, fora do piano, aprendendo a música 'de ouvido' e decidindo exatamente o que quer da obra. Talvez nem todos os detalhes, mas a grande linha fica registrada em minha mente" (KONTARSKY, p. 116, grifo meu).

Conforme observamos a partir das respostas de Buchbinder e Kontarsky, é possível a formação de uma memória auditiva e, além disso, é possível guardar na memória imagens que se formam através dos sons, o que fica bastante claro, por exemplo, quando Kontarsky afirma ficar registrada em sua mente a grande linha (musical).

Kontarsky afirma ainda, em relação à primeira pergunta da entrevista, que decide na primeira leitura o que deseja de 
9. The ability to imagine things that are not real; the ability to form a picture in your mind of something that you have not seen or experienced. uma obra e logo começa a trabalhar os detalhes técnicos. Uma vez que estes estão dominados, ele tenta combiná-los com o material sonoro armazenado em sua imaginaçáo (1998, p. 124, grifo meu). Armazenado em sua imaginação talvez signifique, de fato, armazenado na memória. Todavia, é interessante notar como um termo pode ser substituído por outro, ou seja, o termo "memória" caberia igualmente em sua resposta, o que serve para reforçar a relação entre memória e imaginação ou ainda, memória e imagens, já que "imaginação" tem sua raiz em "imagem". O termo (em inglês) usado na entrevista de Kontarsky é "imagination", definido, segundo o Merriam- Webster's Advanced Learner's English Dictionary (2008), na primeira acepção, como "a habilidade de imaginar coisas que não são reais; a habilidade de formar uma imagem na mente de algo que não se viu ou não se vivenciou"'. Isto nos leva a pensar que o material sonoro presente em sua imaginação é, na verdade, um material sonoro já criado através da habilidade de formar imagens que, por sua vez, ocupam um lugar na memória, o que mais uma vez reforça a relação entre memória e performance de música instrumental.

András Schiff, em sua resposta à escuta durante o ato performático, diz que o pianista, tanto quanto o regente, deve criar um "terceiro par de ouvidos" (apud SCHUEKE, 2015 p. 127). Aqui, o intérprete ativa a memória musical do primeiro e segundo estágios de escuta para controlar o resultado durante a execução. Para ouvir a si mesmo, é necessário que o intérprete saia de si mesmo - mas náo totalmente - e talvez esse seja, de todos os estágios, o mais difícil, pois o distanciamento deve ser equilibrado e consciente: o intérprete deve poder ouvir a si mesmo para controlar suas decisóes com o intuito de atingir o objetivo desejado durante a execução e, ao mesmo tempo, deve ouvir com neutralidade, para saber se o que ele está ouvindo está sendo ouvido por outros de mesma forma ou, pelo menos, de forma semelhante.

O distanciamento, contudo, náo pode ser tal que a execução se torne um protocolo de decisóes, pois dessa forma o intérprete perde em emoção e a música, consequentemente, perde o interesse para a audiência.

O pianista Ivan Davis, em resposta à segunda pergunta da entrevista - adequaçáo do objetivo planejado na primeira escuta - faz uma analogia com o tipo de estudo de Maria 
Callas, e afirma: "a cantora costumava trabalhar partindo de uma ideia geral da peça e depois cantando cada nota no lugar exato, no tempo preciso, articulando bem as palavras para chegar finalmente à inflexão apropriada para cada uma. Ela estudava sem nenhuma emoção, até se sentir segura” (apud CHUEKE, p. 122).

\section{AFETOS, MEMÓRIA E PERFORMANCE}

Considerando a última citação da seção anterior, chegamos a outro ponto relacionado a nosso trabalho: a emoçáo ou os afetos. Para iniciarmos nossa discussáo, perguntamo-nos se, durante o estudo e consequente memorizaçáo de uma peça, o intérprete deveria esforçar-se para memorizar também os afetos expressos naquela peça, e se deveria, também, buscar (re)produzir os afetos ali contidos durante sua performance.

Werckmeister (apud BARTEL 1998, p. 29) afirmava que "a música devia despertar, alterar e acalmar as paixóes ${ }^{10 "}$. A discussão dos afetos remonta à Antiguidade clássica. No âmbito da música, eles passam a ter uma definição mais específica do que "emoçôes".

Concordamos com essa visão, de que a música deva despertar afetos ou emoçóes. Os afetos são discutidos desde a Antiguidade e têm um papel fundamental na música de séculos XVII e XVIII.

A discussão sobre os afetos em música, com base na retórica clássica, destaca-se principalmente nos estudos musicais dos séculos XVI e XVII, por meio das inovaçôes no currículo das Lateinschulen idealizadas por Lutero, quando se procurou dar à música o mesmo tratamento dado ao texto: é de onde vem o conceito musica poetica, que se distingue da musica theoretica e da musica practica.

O termo afeto é a tradução latina de pathos. O vocábulo paixão, advindo também de pathos, adquiriu, ao longo do tempo, um significado mais religioso (por exemplo, Paixáo de Cristo), mas ainda se fala de paixóes para se referir a afetos. $\mathrm{O}$ sentido patológico (palavra também oriunda de pathos) dos "afetos" fica claramente expresso na interpretaçáo latina deste vocábulo por Cícero, que o reproduz (ou traduz) por perturbatio animi, ou seja, perturbação da alma.
10. "Werckmeister asserted that music "is ordered to arouse, correct, alter, and calm the passions, p. 29. In: Andreas Werckmeister, Musicalisches SendSchreiben (Quedlinburg, 1700 , p. 11)". Nossa tradução. 
11. "The Baroque affective musical devices were considered learnable and teachable, analogous to the mathematical and rhetorical-linguistic aspects of music theory. In order to have access to and take advantage of music's affective power, it was considered possible to undertake a rational analysis of music and to objectively identify its God-given power. The German Baroque composer still viewed the act of composition as a craft rather than an aesthetic undertaking". Nossa tradução.
No prefácio à Retórica das Paixóes - nome dado ao segundo livro da Retórica de Aristóteles, numa ediçáo especial -, Meyer, no prefácio, define do seguinte modo a paixão:

A paixão é decerto uma confusão, mas é antes de tudo um estado de alma móvel, reversível, sempre suscetível de ser contrariado, invertido; uma representação sensível do outro, uma reação à imagem que ele cria de nós, uma espécie de consciência social inata, que reflete nossa identidade tal como ela se exprime na relação incessante com outrem (MEYER, 2000, p. XXXIX).

Temos que levar em conta que, no âmbito da música, e aqui nos referimos de forma especial àquela composta entre os séculos XVI e XVII, a teoria dos afetos ou, ainda, o seu "ensino", remetia à teoria médica grega antiga, como, por exemplo, os escritos sobre as enfermidades sagradas de Hipócrates. De acordo com as teorias antigas, há quatro temperamentos humanos distintos: o melancólico, o sanguíneo, o colérico e o fleumático, cada um com suas peculiaridades, como, por exemplo, elementos, atributos, estaçáo do ano, afetos etc.

Em relação aos expedientes afetivos musicais, Bartel afirma:

Os expedientes afetivos musicais podiam ser ensinados e aprendidos, analogamente aos aspectos matemáticos e retórico-linguísticos da teoria musical. Com o intuito de ter acesso ao poder afetivo da música e tirar proveito deles, considerava-se possível empreender-se uma análise racional da música e a identificar objetivamente o seu poder dado por Deus. $\mathrm{O}$ compositor alemão do Barroco considerava o ato de compor mais como uma arte do que como uma tarefa estética ${ }^{11}$ (BARTEL, 1998, p. 34).

Desta citação interessa-nos o termo análise racional. Com isso, quer se dizer que a construçáo musical era objetiva. À época não predominava a concepção de inspiração para compor, algo mais próprio ao Romantismo: através do programa de preceito, exemplo e imitação, a arte de composição no Barroco alemão é um processo mais objetivo que subjetivo, assim como se torna mais objetiva e racional a inclusão de afetos na composiçáo. Resta saber se a objetividade predominava também no campo da performance.

Não diríamos que há uma oposição entre a música renascentista e a música barroca. Náo podemos apontar as diferen- 
ças ou, ao menos, uma diferença que seja importante para nossa discussão, sem levarmos em conta o contexto de cada um dos períodos: no Barroco, a música instrumental ganha terreno, e assim começam a surgir os primeiros concertos para instrumentos, algo que continuaria até o Romantismo. A diferença nas composiçóes da Renascença para o Barroco que queremos apontar aqui diz respeito aos afetos. Bartel diz:

Embora o papel afetivo da música tenha se mantido fundamental na Renascença quanto no Barroco, o entusiasmado espírito do Barroco exigia uma expressividade intensificada. $\mathrm{O}$ equilíbrio entre texto e música - próprio da Renascença - foi incomodado, resultando num maneirismo musical que exagerava a função da expressão do texto para além dos limites do ideal artístico renascentista. Enquanto a Renascença buscava representar uma visão equilibrada dos afetos, o Barroco pretendia despertar e mover o espírito humano a esses extremos passionais. A música devia criar ativamente os afetos pretendidos, e não refleti-los de forma passiva. As composiçóes deviam tanto representar quanto despertar os afetos no ouvinte. Ao objetivo affectus exprimere, da Renascença, o Barroco acrescentou o de affectus movere ${ }^{12}$ (BARTEL, 1998, p. 32).

Vemos, assim, que o papel do compositor barroco se diferencia do papel do compositor renascentista principalmente com relação a seu ponto de chegada: o ouvinte, e náo mais o texto em si, pois é sua função, através dos afetos contidos na música, levar o ouvinte a sentir as mesmas emoçóes.

No entanto, tratar um afeto de forma táo racional a ponto de acreditar que possa levar ao mesmo estado emocional todos os ouvintes seria senso comum - embora isto seja de fato esperado -, pois a recepçáo musical depende, inclusive, de quanto o ouvinte consegue escutar e de todas as suas outras referências, pessoais e musicais. Além disso, devemos considerar que existem, segundo os gregos antigos, quatro tipos de temperamentos diferentes, que indicamos acima. De acordo com o seu temperamento, cada um receberá de forma diferente o afeto expresso na música. A esse respeito, Bartel diz:

As diferentes reações dos ouvintes ao ouvirem a mesma música também era racionalmente explicada. Os temperamentos oscilantes de indivíduos diferentes os predisporiam a reaçóes mais fortes em relação a diferentes afetos. Por exemplo, uma pes-
12. "Although the affective role of music remained fundamental throughout both the Renaissance and the Baroque eras, the exhilarated spirit of the Baroque called for a heightened expressiveness. The Renaissance balance between text and music was disturbed, resulting in a musical mannerism which exaggerated the role of text expression beyond the limits of the Renaissance artistic ideal. While the Renaissance sought to portray a balanced view of the affections, the Baroque wanted to arouse and move the human spirit to this passionate extremes. Music was actively to create the intended affections, not just passively reflect them. Compositions were to both portray and arouse the affections in the listener. To the Renaissance affectus exprimere the Baroque added affectus movere". Nossa tradução. 
13. 'Listeners' different reactions to hearing the same music was also rationally explained. The varying temperaments of different individuals would predispose them to stronger reactions to different affections. For example, a melancholic person would react much more readily and vehemently to melancholic music than would someone of a choleric character". Nossa tradução. soa melancólica reagiria muito mais pronta e veementemente à música melancólica do que alguém com um caráter colérico ${ }^{13}$ (BARTEL, 1998, p. 39).

Em consonância com o que se apresenta na citação anterior, Lima, ao discutir a Retórica de Aristóteles, aponta-nos que:

o Estagirita observa a importância de o orador saber despertar em cada auditório a paixáo que melhor sirva aos interesses de seu discurso, pois os mesmos fatos podem ser assimilados em diferentes sentidos, dependendo da situação e conforme possíveis disposições distintas de sentimentos do ouvinte (LIMA, 2011, p. 101).

Basta compararmos a figura do intérprete musical à do orador para percebermos que também ele deve se preocupar com o tipo de público (cada auditório). Acreditamos que as "possíveis disposiçóes distintas de sentimentos do ouvinte" remetem-nos aos "temperamentos oscilantes de indivíduos diferentes" e, no caso da música, não lidamos com o interesse do discurso (musical), mas, de modo direto, com sua própria essência.

Questionamo-nos, aqui, se o intérprete, possuidor - tanto quanto seu público - de um caráter, de uma personalidade e de um temperamento específico, deve programar suas emoçóes, no ato da performance, para (re)produzir ou (re)criar a sequência de afetos presente na peça a ser executada. Essa programação de sua emoção pode se referir a uma "memorização" de um quadro de emoçóes que ocorrerá em determinada sequência. Assim, é possível falarmos aqui de "memorização de afetos" com vistas à performance musical. Se considerarmos que o princípio da música, principalmente da música renascentista e barroca, é despertar e mover os afetos, parece não restar outra opção ao intérprete: terá, realmente, de planejar, em seus estágios de escuta e memorizaçáo, como esses "afetos" seráo despertados através de sua performance.

Ao buscar o planejamento dos afetos a serem despertados, movidos, o intérprete deve, em primeiro lugar, ater-se ao "tipo" de composição ou material composicional: vemos aí outro elemento de ligação entre a música e a retórica, a saber, o gênero do discurso, definido pelos elementos que o compóem. Sobressai aqui o princípio da adequação, ou seja, o intérprete deve despertar determinados afetos e de certo modo que 
não seja divergente do tipo de composição que tem em mãos. Ele não apenas deve controlar como despertará os afetos, mas também suas próprias paixóes, para "atingir" a audiência. Veja a possibilidade da comparação com o que diz Lima:

Por outro lado, o retor também precisa ter domínio de si mesmo a fim de náo sentir paixóes que náo estejam condizentes com o discurso por ele proferido. Diante de tal importância que a paixão assume, Aristóteles propóe que ela seja racionalmente identificada e orientada pelo retor, e que os sentimentos do auditório sejam colocados em sintonia com as ideias que ele (o retor) defende (LIMA, 2011, p. 102).

O terceiro estágio de escuta - o ato performático - exige do intérprete a memória da sequência de afetos que quer despertar, em consonância com a natureza da peça e com os seus objetivos dos estágios anteriores de escuta. Ao que parece, é possível haver uma "relativizaçáo" dos afetos pelo filtro de suas próprias emoçóes ou paixóes: do estado emocional do intérprete no início de sua performance depende de que modo e com que intensidade os outros afetos seráo despertados durante a execução. Assim, parece não ser prudente que o intérprete inicie num estado emocional alterado; antes, parece ser necessário, no processo de "relativizaçáa", o uso da razáo. Vejamos como isso é indicado por Lima:

Sobre a importância da razão na orientação das paixôes, Aristóteles (Ret. III, VII, 10), após dizer que o orador deve antecipar-se, prevendo a censura dos outros, propóe alguns remédios para evitar excessos e inconvenientes estilísticos. [...] O filósofo deixa clara a importância de um autocontrole emocional, podendo este reverberar na disposição do corpo e da voz, que só é possível naqueles cuja racionalidade é preponderante, pois é preciso ter a razáo sempre atenta e pronta para evitar inconvenientes que possam desvirtuar as práticas discursivas. Ocorrendo assim, harmonizando a relação entre intelecto e paixôes, o ser humano tende a sentir que essas duas instâncias são complementares entre si na busca pela felicidade. Em outras palavras, é preciso manter as paixôes em equilíbrio para pensar com lucidez; é fundamental pensar com lucidez para manter as paixóes em equilíbrio (LIMA, 2011, p. 110-111). 
E como o mesmo procedimento se reflete na arte musical, segundo Carl Philipp Emanuel Bach em seu Ensaio sobre a maneira correta de tocar teclado:

\$13.Um músico não provoca emoçôes se não estiver emocionado: é indispensável que ele se coloque em todos os afetos que quer evocar nos seus ouvintes e dê a entender seus sentimentos, para poder compartilhá-los melhor. Em trechos doces e tristes, ele deve ficar doce e triste. Deve-se ver e ouvir isso. Deve-se tomar muito cuidado aqui para não retardar e arrastar demais. Facilmente se incorre nesse erro, através de muito afeto e melancolia. O mesmo ocorre com trechos animados, alegres, ou de outros tipos, em que o músico deve se colocar nesses afetos. Logo que ele exprimiu uma ideia, surge outra e, assim, sem cessar, ele deve transformar suas paixóes (BACH, 2009 [1753], p. 137).

Como percebemos do final da citaçáo, "logo que ele exprimiu uma ideia, surge outra e, assim, sem cessar, ele deve transformar suas paixôes", o intérprete, no ato da performance, precisa ativar a memória musical - que inclui os afetos memorizados -, devendo estar num estágio intermediário entre a emoção e a razão, preparado para "transformar suas paixóes", conforme exigido pela composiçáo que executa.

Ainda que alguns sejam tentados a sustentar o pensamento de que o intérprete - assim como o orador e assim como o ator - simula uma sequência de afetos (emoçóes) de forma planejada, sem se envolver de fato com o que faz, outros afirmam que, sem se emocionar, o intérprete não consegue transmitir a "verdade" da música que executa. Parece-se exigir do intérprete que conduza os ouvintes pelos mesmos caminhos trilhados com o auxílio de suas emoçóes, ou seja, auxílio das emoçóes que desperta em seus ouvintes, e que devem, ao que parece, ser as mesmas do próprio intérprete. Lima, ao discorrer sobre características específicas da narração de acontecimentos, indica que a audiência deve sentir as mesmas emoçóes que o orador, como vemos abaixo:

Isto (narrar acontecimentos passados como se estivessem presentes) implica em um conhecimento acerca das paixôes e de como elas podem ser movidas pelo discurso. Esse conhecimento não é mero coadjuvante entre os elementos da tríade aris, pois a sua sábia aplicação pode ocasionar a aproximação entre os sentimentos dos vários participantes de um auditório, estreitando também 
a distância entre o retor e os seus ouvintes. Nessa perspectiva, o objetivo do retor é fazer com que todos os presentes sintam-se imbuídos da mesma paixão que por ele (orador) é sentida. [...] Assim, o ideal é que a retórica desperte e conduza a paixão que se harmoniza ao discurso e, ao mesmo tempo, quanto mais presente se faz a paixão, mais ela inspira o próprio discurso que a despertou (LIMA, 2011, p. 102).

No âmbito musical, Carl Ph. E. Bach (2009) demonstra sua exigência para com o intérprete - em relaçáo a despertar nos ouvintes afetos semelhantes aos seus - no seguinte trecho:

$\$ 14$ Da quantidade de afetos que a música pode evocar, percebem-se os dons especiais que um músico perfeito deve possuir e a grande sensibilidade com que ele os deve empregar se quiser levar em conta os ouvintes, a percepção que eles teráo do verdadeiro caráter de sua execução, o lugar e outros fatores. A natureza deu tal diversidade à música, que todos podem participar dela; portanto, todo músico deve, tanto quanto possível, satisfazer todo tipo de ouvinte (BACH, 2009 [1753], p. 137).

\section{ALGUMAS PALAVRAS}

O objetivo principal deste trabalho foi, como vimos, traçar uma relação entre memória, afetos e a performance musical. Para tanto, lançamos máo de investigaçóes acerca da memória, predominantemente na $R h$. ad Herennium, de autoria anônima, obra mais importante para esta quarta parte da Retórica (de acordo com sua divisão clássica), conforme apontado por Yates (2007), porém buscamos apoio também na filosofia antiga, com base principalmente no Livro I da Metafísica de Aristóteles e no que estudiosos dizem acerca da teoria da reminiscência em Platáo e neste último filósofo.

Uma vez tendo discorrido sobre a memória, deixando transparecer ainda um princípio de discussão sobre a importância dos órgãos de sentido, passamos a investigar os estágios de escuta, com base em Chueke (2015), cujo trabalho nos trouxe comentários de aclamados pianistas sobre os estágios de escuta.

Acreditamos que, na música poética, os afetos são mais perceptíveis, já que essa música sempre é "acompanhada" de um texto e, desse modo, reflete os afetos dos poemas ou 
textos que lhes servem de base. Fomos um pouco além em nossas investigaçóes e extrapolamos, por essa razão, o período específico da música poética. Todavia, com isso pudemos demonstrar que acreditamos que a música, mesmo a partir do século XVIII, ainda que considerada por grandes estudiosos um objeto "exclusivo" da Estética, não está vazia de elementos que podem ser concebidos ou percebidos como retóricos, principalmente no tocante às expressivas figuras.

Assim, com as respostas dos pianistas entrevistados por Chueke (2015), introduzimos paulatinamente a discussáo sobre os afetos, ao que parece, "planejados" nos estágios de escuta e, por conseguinte, "memorizados". A grande pergunta de nossa investigação foi se o intérprete, no ato performático, (re) produz um sequência de afetos "memorizada”, chegando a um ponto, para nós, crucial: reunir na discussão as consideraçôes acerca de memória e afetos (e memorização de afetos) no ato performático, tendo-nos apoiado, para isso, principalmente em Bartel (1998), Lima (2011) e Carl Ph. E. Bach (2009).

Se podemos apontar alguma conclusão, é a de que o intérprete memoriza, naturalmente, a sequência de afetos presente na obra que executará, e que deve buscar um meio termo entre emoção e razão para, conscientemente, transmitir os afetos da peça que executa durante sua performance.

A "performance" é resultado de um processo anterior ao "ato performático": remonta a um planejamento de que fazem parte a memória e os afetos: a memória, na medida em que o próprio ato de leitura de uma partitura remete a imagens (acústicas ou formadas a partir do som) para a produção de novas imagens em lugares específicos nessa mesma memória. Ou seja, a memória pode se reorganizar ou se dilatar durante a leitura de uma partitura. No caso de uma leitura longe do instrumento, o elemento primordial é a memória, onde estáo armazenados os sons e as imagens acústicas ou produzidas a partir de sons (internalizados).

Existe uma relação estreita entre a criação de imagens na memória e os afetos, pois os afetos condicionam a criaçáo das imagens: é a partir deles, principalmente, que o intérprete, no ato de leitura, define seus critérios de interpretaçáo da peça a ser executada. $\mathrm{E}$ os afetos do intérprete, que interferem no planejamento de seu objetivo para a peça, condicionam-se, 
por sua vez, aos afetos próprios a este intérprete, que possui certo temperamento.

As escolhas do intérprete, de tipos de toque para trechos isolados ao tipo de construçáo frasal, devem estar em consonância com os afetos da peça a ser executada, se se pretende, através deles, mover aquele que ouve.

Essas escolhas, dependentes dos afetos, remetem à memória do intérprete, que terá de evocar imagens acústicas ou provenientes do som para que os afetos da peça sejam devidamente produzidos.

Assim, no ato performático de música instrumental, a memória - incluindo-se aí a memória das imagens criadas para a sequência de afetos da peça em execução - é imediatamente acessada. Parece-nos que, para que se execute com certa distinção uma peça, é necessário que se busque um ponto de equilíbrio entre razão e emoção: este ponto conduzirá a realização ([re]criação) dos afetos presentes na música executada.

\section{REFERÊNCIAS BIBLIOGRÁFICAS}

ARISTÓTELES. Metafísica (Livro I e Livro II). São Paulo: Abril Cultural, 1984. Trad.Vincenzo Coceo e notas de Joaquim de Carvalho (col. Os Pensadores).

Retórica das Paixóes. São Paulo: Martins Fontes, 2000 (trad. Isis Borges B. da Fonseca).

BACH, Carl Philipp Emanuel. Ensaio sobre a maneira correta de tocar teclado. Berlim, 1753-1762. Tradução de Fernando Cazarini. Campinas [Berlin]: Ed. da Unicamp [Christian Friedrich Henning], 2009 [1753].

BARTEL, Dietrich. Musica Poetica. Musical-Rhetorical Figures in German Baroque Music. Nebraska: University of Nebraska Press, 1998.

BERNS, J.J., NEUBER, W. (ed.): Bibliogr. der Quellenschr. zur Mnemonik bis 1700. In: UEDING, Gert (ed.). Historisches Wörterbuch der Rhetorik. Tübingen: Max Niemeyer, 2001 (v. 5).

CHUEKE, Zelia. Estágios de Escuta Durante a Preparação e a Execução Pianística na Visão de Seis Pianistas de Nosso Tempo. In: RAY, Sonia (org.) Performance Musical e suas Interfaces. Goiânia: Vieira, 2015, p.111-138. 
ÉPICURE. Lettres et Maximes. Paris: Presses Universitaires de France, 2009 [1977]. Trad. Marcel Conche.

EWEN, David. Dictators of the Baton. Chicago: Zift-Davis Publishing Company, 1943.

FIGUEIREDO, Maria José. Aristóteles e a teoria da reminiscência. Philosophia, Lisboa, v. 2, p. 43-52, 1993. Disponível em: < http://www.centrodefilosofia.com/uploads/pdfs/43-52. pdf $>$. Acesso em: 7 jan. 2016.

KONTARSKY, Alfons. Programmnoten. Internationale Sommerakademie Mozarteum. Salzburg, 13 de jul. 1998.

LIMA, Marcos Aurélio de. A Retórica em Aristóteles: da orientação das paixóes ao aprimoramento da eupraxia. Natal: IFRN, 2011.

LONG, A. A.; SEDLEY, D. N. Die hellenistischen Philosophen. Texte und Kommentare. Stuttgart und Weimar: Metzler, 2000 (trad. Karlheinz Hülser).

MERRIAM-WEBSTER'S. Advanced Learner's English Dictionary. United States of America, 2008.

RETÓRICA A HERÊNIO [Rhetorica ad Herennium]. São Paulo: Hedra, 2005 (trad. Ana Paula Celestino Faria e Adriana Seabra).

SCHÖNBERG, Arnold. Style and Idea. Berkeley and Los Angeles: University of California Press, 1984.

SCHUMANN, Robert. Music and Musicians. New York: Pantheon Books, 1952 [1946].

SOUZA, José Cavalcante de. A reminiscência em Platáo. Discurso, Sáo Paulo, v. 1, n. 2 p. 51-67, 1971. Disponível em: < http://www.revistas.usp.br/discurso/article/view/37720 >. Acesso em: 5 jan. 2016.

UEDING, Gert, J.J.Berns e W.Neuber (eds.): Bibliografie der Quellenschrift zur Mnemonik. Drücke bis 1700 (2002). In: Historisches Wörterbuch der Rhetorik. Tübingen: Max Niemeyer Verlag, 2001 (v. 5).

YATES, Frances A. A Arte da Memória. Campinas [London]: Ed. da Unicamp [Warburg Institute], 2007 (trad. Flavia Bancher). 